Population Study

Poster

Abstract ID: 37

\title{
The application of the theory of planned behavior to understand the intention of weight loss practice among overweight adolescents
}

\author{
Suriati Binti Sidek $^{\mathrm{a}} \mid$ Ajau Danis $^{\mathrm{b}} \mid$ Safiah Md Yusof ${ }^{\mathrm{b}}$ \\ anternational Islamic University Malaysia \\ ${ }^{b}$ Universiti Teknologi MARA Malaysia
}

Introduction: Overweight adolescents have been reported to struggle in losing weight. However, their intention to engage in weight loss practice remains unclear. Therefore, the aim of this qualitative study was to understand the factors that lead to the intention of weight loss practice among overweight adolescents using the Theory of Planned Behavior (TPB). Methods: Thirty-three overweight adolescents aged between 13 to 17 years old were recruited from three secondary schools in Selangor. They responded to a semistructured interview based on TPB that has three core antecedents; i) Attitude toward the behavior, ii) Subjective norm, and iii) Perceived behavioral control. Results: There is a high possibility that overweight adolescents will perform weight loss practice if the diet plans they followed, or physical activity they performed, or slimming product they consumed prove to make them lose some kilograms (Attitude). Besides that, the social pressure received from social interactions with parents and peers in a form of weightrelated criticisms and weight-related teasing may encourage overweight adolescents to be thin and reducing weight (Subjective norm). Finally, the emergence of intention that subsequently lead to weight loss practice is either driven by social interactions and media influences, or limited by some of the identified barriers (Perceived behavior control). Conclusions: The TPB is suggested to be an effective framework to understand the intention of weight loss practice among overweight adolescents, allowing for the development of obesity intervention program.

KEYWORDS: Adolescents; Obesity; Theory of Planned Behavior; Weight loss practice 